Review Article

\title{
Sepsis and Oxidative Stress in the Newborn: From Pathogenesis to Novel Therapeutic Targets
}

\author{
Chiara Poggi ${ }^{1}{ }^{1}$ and Carlo Dani $\mathbb{D I D}^{1,2}$ \\ ${ }^{1}$ Division of Neonatology and Neonatal Intensive Care, Department of Mother and Child Care, Careggi University Hospital, \\ Florence, Italy \\ ${ }^{2}$ Department of Neurosciences, Psychology, Drug Research, and Child Health, University of Florence, Florence, Italy
}

Correspondence should be addressed to Chiara Poggi; poggich@gmail.com

Received 23 February 2018; Revised 4 June 2018; Accepted 13 June 2018; Published 2 August 2018

Academic Editor: Daniela Pellegrino

Copyright (c) 2018 Chiara Poggi and Carlo Dani. This is an open access article distributed under the Creative Commons Attribution License, which permits unrestricted use, distribution, and reproduction in any medium, provided the original work is properly cited.

\begin{abstract}
Sepsis is at present one of the leading causes of morbidity and mortality in the neonatal population. Together with inflammation, oxidative stress is involved in detrimental pathways activated during neonatal sepsis, eventually leading to organ dysfunction and death. The redox cascade during sepsis is mainly initiated by IL- 6 and IL- 8 stimulation in newborns and includes multiple noxious processes, as direct cell damage induced by reactive oxygen species, activation of gene expression leading to amplification of inflammation and oxidative stress, and impairment of mitochondrial function. Once proinflammatory and prooxidant pathways are established as stimulated by causing pathogens, self-maintaining unfavorable redox cycles ensue, leading to oxidative stressrelated cellular damage, independently from the activating pathogens themselves. Despite antioxidant systems are induced during neonatal sepsis, as an adaptive response to an increased oxidative burden, a condition of redox imbalance favoring oxidative pathways occurs, resulting in increased markers of oxidative stress damage. Therefore, antioxidant treatment would exert beneficial effects during neonatal sepsis, potentially interrupting prooxidant pathways and preventing the maintenance of detrimental redox cycles that cannot be directly affected by antibiotic treatment. Among others, antioxidant agents investigated in clinical settings as adjunct treatment for neonatal sepsis include melatonin and pentoxifylline, both showing promising results, while novel antioxidant molecules, as edaravone and endothelin receptor antagonists, are at present under investigation in animal models. Finally, mitochondria-targeted antioxidant treatments could represent an interesting line of research in the treatment of neonatal sepsis.
\end{abstract}

\section{Introduction}

Despite general improvement in intensive care of acutely ill newborns, sepsis is still among the leading causes of death in the neonatal population worldwide [1]. On a whole, neonatal sepsis was reported to occur in 1 every 1000 live births [2]; however, incidence as high as 3\% to $20 \%$ were reported in the population of preterm newborns, due to the presence of multiple coexisting risk factors for nosocomial sepsis [3]. Mortality due to neonatal sepsis is strictly dependent on the causative pathogen and on the gestational age of the patients, with a mortality rate as high as $20 \%$ observed in very preterm newborns $[2,3]$.
According to the guidelines of the International Pediatric Sepsis Consensus Conference, neonatal sepsis is defined as a clinical syndrome characterized by the presence of both infection and systemic inflammatory response syndrome (SIRS) $[4,5]$. SIRS includes inadequate core temperature stability, tachycardia or bradycardia, tachypnea or unexplained need for mechanical ventilation, and leukocyte count elevated or depressed for postnatal age [4]. It is at present widely accepted that the infective insult due to the invasion of sterile tissues by pathogens merely represents the initiation of sepsis, while the process leading to the sepsis syndrome is subsequently maintained by a cascade of inflammatory and oxidative mechanisms that, once activated, act independently from the presence of the pathogens themselves [6]. 
It was demonstrated that, at least in adults, the immune system shows a typical two-phase response during sepsis, characterized by an initial increase of proinflammatory mediators followed by a shift towards anti-inflammatory cytokines, anergy of T-cells, and also apoptosis-induced loss of cells of the adaptive immune system in the most severe cases [7]. Activation of the immune system during sepsis is paralleled by a complex chain of redox events in both adults [8] and newborns [9], which partially differ among the two populations. The redox cascade initiated by immune activation includes generation of consistent amount of reactive oxygen species (ROS) and reactive nitrogen species (RNS), activation of DNA transcription processes, and mitochondrial functional impairment, eventually leading to multiple organ dysfunction and death $[8,9]$.

\section{Redox Status in Neonatal Sepsis}

2.1. The Redox Sepsis Cascade. While tumor necrosis factoralpha (TNF-alpha) plays a pivotal role in the onset of adult sepsis [8], interleukin- (IL-) 6 and IL-8 represent the cytokines mainly involved in the initiation of the sepsis cascade in the newborn [9]. Levels of IL-6 and IL-8 are significantly increased in septic newborns in comparison to healthy controls, in both early-onset (EOS) and late-onset sepsis (LOS) $[10,11]$ at least for the first 12-24 hours from the onset of sepsis [10], and were proposed as useful markers for the early diagnosis of sepsis in newborns in experimental settings, and, when available, also in clinical practice [11, 12]. However, recent evidences suggest that the cytokines expression profile may consistently differ among septic newborns, according to the timing of sepsis presentation and to the patients' gestational age. In a small cohort of term and late preterm newborns, TNF-alpha increased in both EOS and LOS in comparison to healthy controls, but only patients with LOS showed also increased levels of IL-6 and IL-10 [13]. Moreover, while proinflammatory cytokines as TNFalpha and IL- 6 were upregulated in the acute phase of sepsis, anti-inflammatory cytokines as IL-4 and IL-10 were preferentially overexpressed during the subacute phase [13], providing evidence that the two-phase immune response, typical of adult sepsis, would likely occur also in newborns. The comparison of immune response during sepsis in preterm newborn $\geq 32$ or $<32$ weeks of gestational age showed that mediators of innate immune response, as C-reactive protein (CRP) and SC5b-9, are increased in both groups, but proinflammatory cytokines as interferon-gamma, TNFalpha, and IL- 6 are upregulated only in the subgroup with gestational age $\geq 32$ weeks, while both groups showed increased levels of anti-inflammatory cytokines, as IL-4 and IL-10 [14]. The differential profile of cytokines expression during sepsis suggests that partially different pathways could be involved in the initial trigger of the sepsis process at different gestational ages.

It has been proposed that, following the release of proinflammatory cytokines, several oxidative stress-related pathways are activated through different mechanisms, triggering the initiation of a self-maintaining "sepsis redox cycle," finally leading to cell oxidative damage and mitochondria impairment [9]. According to this model, the cytokineinduced activation of nuclear factor kappa-light-chainenhancer of activated B cells $(\mathrm{NF}-\kappa \mathrm{B})$ constitutes the first step of the process [9]. Several observations are consistent with $\mathrm{NF}-\kappa \mathrm{B}$ activation during neonatal sepsis $[15,16]$, and in a mouse model of group B Streptococcus neonatal sepsis, the pathway mediated by c-Jun N-terminal kinase was demonstrated to play a pivotal role in the orchestration of inflammation during sepsis, as its inhibition significantly suppressed proinflammatory cytokines production [17]. Similarly, it was recently demonstrated that protein kinase $\mathrm{D}$ is essential for NF- $\kappa \mathrm{B}$ pathway activation during group $B$ Streptococcus sepsis [18]. NF- $\kappa$ B acts as a powerful transcription factor which binds to DNA and activates the transcription of several different genes including inducible nitric oxide synthase (iNOS) and cyclooxygenase 2 (COX-2) [8, 9], leading to increased production of nitric oxide (NO) and superoxide, respectively [9]. Superoxide levels are further increased by the cytokine-induced direct activation of NADPH oxidase [9]. In a cardiomyocyte model of neonatal sepsis, challenge with Gram-negative lipopolysaccharide (LPS) induced NADPH overexpression, leading to COX-2 overexpression through a MAP-kinase/NF- $\kappa \mathrm{B}$-dependent mechanism [19]. Therefore, both direct activity of NADPH oxidase and NADPH-induced COX-2 upregulation can contribute to increase cytoplasmic superoxide [6]. Superoxide is then dismutated to $\mathrm{H}_{2} \mathrm{O}_{2}$ by cytoplasmic $\mathrm{CuZn}$-superoxide dismutase (SOD) [6]. In a neonatal mouse model of sepsisinduced lung injury, LPS-induced lung cytokines expression, neutrophils influx, and NF- $\kappa \mathrm{B}$ translocation were suppressed in NADPH oxidase-deficient animals [20]. Consistent with these observations, also LPS-induced matrix metalloproteinase expression was reduced, as well as alveolar adverse remodeling characterized by reduced number of alveoli and complexity of lung alveolarization [20]. These observations suggest that NADPH oxidase may play a key role in determining the disruption of lung architecture, typical of bronchopulmonary dysplasia (BPD) [21] in septic preterm newborns.

Increased levels of NO were demonstrated in neonatal sepsis [22, 23]. Particularly, preterm newborns $<27$ weeks of gestational age presented lower basal levels of $\mathrm{NO}$ in comparison to more mature patients, but produced larger amounts of $\mathrm{NO}$ during the first 2 days of bacteremia, suggesting that both the basal production of $\mathrm{NO}$ and the modulation of NO production may be related to gestational age [23]. In a cohort of term or near term newborn with EOS, circulating NO was significantly higher in comparison to controls [24]. Moreover, iNOS-deficient mice model presented lower degree of inflammation following exposure to Escherichia coli [25], and iNOs overexpression was also demonstrated by real-time PCR in neonatal respiratory epithelial cells challenged with Staphylococcus aureus and Staphylococcus epidermidis, together with proinflammatory cytokines upregulation [26].

NO, along with ROS, directly inhibits electron transport chain in the mitochondria $[27,28]$, resulting in impaired energy production and accumulation of mitochondrial superoxide $[9,27,28]$. Mitochondrial dysfunction was 
demonstrated to be the central core of deleterious proinflammatory and prooxidant routes in adult sepsis [8]. Within the mitochondrion, superoxide can react with $\mathrm{NO}$ to produce peroxinitrite, which in turn decomposes to hydroxyl radical and nitrogen dioxide [9]. These highly reactive species further affect mitochondrial functionality [9], and in cellular model of neonatal sepsis, peroxinitrite was shown to suppress mitochondrial function [29], thus favoring the maintenance of a detrimental pathway within the mitochondrion itself. Alternatively, superoxide anion derived by dysfunctional electron transport chain (ETC) can undergo dismutation to $\mathrm{H}_{2} \mathrm{O}_{2}$ by $\mathrm{MnSOD}$ within the mitochondrion, which is then released in the cytosol [9]. Therefore, as a result of NADPH oxidase activity, COX-2 overexpression, and dysfunctional mitochondrial ETC, increasing amounts of $\mathrm{H}_{2} \mathrm{O}_{2}$ accumulate in the cytosol and activate NF- $\kappa \mathrm{B}$, thus completing a detrimental self-maintaining redox loop [9].

In preterm newborns, oxidative pathway activation during sepsis would interact with a preexisting prooxidant state. Increased ROS production was demonstrated in preterm newborns, resulting from hyperoxic events and mechanical ventilation [30-32], and prematurity is well known to be associated with increased risk of oxidative stress-related diseases, as BPD and retinopathy of prematurity [31]. On the other hand, impaired antioxidant capacities were demonstrated in preterm newborns, both because of inappropriate interruption of placental-fetal transfer of antioxidant molecules and insufficient endogenous production [32]. In fact, fetal levels of antioxidant enzymes (AOEs) as $\mathrm{SOD}$, catalase (CAT), glutathione peroxidase (GPx), and glutathione reductase (GR) progressively increase during gestation, paralleling the maturation of surfactant system and preterm animal models fail to induce SOD and GPx in response to oxidative challenges [33,34], in contrast to term newborns, who were demonstrated to induce AOEs in case of fetal distress [35] or resuscitation with high $\mathrm{FiO}_{2}$ [36]. The imbalance of the redox status favoring prooxidative pathways in preterm newborns during sepsis could also be implicated in the pathogenesis of BPD and of the longterm neurodevelopmental sequelae observed in this population following a septic event [37]. Despite the exact pathogenetic mechanisms leading to long-term adverse outcomes in septic newborns remain to be elucidated, it has been proposed that both direct increase in oxidative burden and activation of apoptosis would play a major role in tissue impairment [8]. During ongoing development of the central nervous system, a fall in ATP levels and an increase of prooxidant species, resulting from deleterious redox cycles, would critically affect the functionality and permeability of the mitochondria [38]. Particularly, the release of cytochrome $\mathrm{c}$ from the mitochondria to the cytosol would activate apoptosis through caspase-mediated signaling pathways [39]. Noticeably, caspases, elements of the proapoptotic Bcl-2 family, and the apoptotic protease activating factor 1 were demonstrated to be overexpressed in neonatal brain tissue in comparison to adult brain tissue [39], indicating preferential activation of proapoptotic pathways in newborns following a noxious stimulus. Oligodendrocyte progenitors and subplate neurons, which are the cell species predominantly involved in the pathogenesis of white matter injury and periventricular leukomalacia in newborns, were proved particularly vulnerable to oxidative stress [40,41]. Apoptosis of such cell species would also be implicated in the occurrence of visual impairment, as it would detrimentally affect the development of the optic nerve and of the visual cortex [40,42]. Analogously, oxidative damage and apoptosis have been proposed to be involved in the pathogenesis of long-term respiratory morbidities, as BPD, since increased oxidative burden and exaggerated aspects of apoptosis were demonstrated in newborns with respiratory diseases [43-45]. In lung tissue, activation of apoptosis would result in arrest of the normal process of alveolarization, which is the typical lesion of new BPD [21].

Despite mitochondrial impairment has not been specifically investigated in the newborn, such mechanism could be relevant in the setting of neonatal sepsis. In animal models, neonatal endotoxemia was associated with impairment of carnitine palmitoyltransferase I, the enzyme that controls the entry of fatty acids into the mitochondrion and the rate of fatty acid oxidation, in the developing heart and kidney [29]. The activity of the enzyme measured in mitochondria isolated from the heart, but not from the kidney, of septic newborn rats was significantly impaired, likely because of deleterious effects of ROS on ETC [29]. Moreover, treatment with glutamine, an antioxidant agent that increases Krebs cycle intermediates and supports oxidative phosphorylation, was proved effective in reducing the circulating levels of TNF-alpha and IL-10 in newborn rats exposed to LPS, although it exerted no effect on lipid peroxidation markers and NO production [46]. These results are consistent with the previous observation of restored mitochondrial ultrastructure following exposure to glutamine treatment in a cellular model of neonatal sepsis [47]. The aspect of mitochondrial dysfunction during sepsis could be of major importance in the population of preterm newborns, as they exhibit differential basal mitochondrial functionality in comparison to term newborns [48]. Particularly, the activity of complex III and IV of respiratory chain, pyruvate dehydrogenase and citrate synthase measured on muscle mitochondria obtained from autopsy, was proved to be markedly lower in preterm newborns in comparison to older children, suggesting an age-dependent functionality of mitochondrial respiratory chain [48], which would expose more preterm newborns to an increased risk of energy deficit, and thus organ failure, particularly in case of superimposed mitochondrial impairment during sepsis.

\subsection{Markers of Oxidative Stress and Antioxidant Defense.} The profile of circulating markers of oxidative stress and of enzymatic and nonenzymatic antioxidant defenses during neonatal sepsis has been less extensively studied in comparison to adult patients (Table 1). In septic newborns, circulating levels of TNF-alpha and malondialdehyde (MDA), a common marker of polyunsaturated fatty acid peroxidation, were shown to be significantly increased in comparison to healthy controls $[49,50]$ along with antioxidant enzymes xanthine-oxidase, SOD, and GPx, while peroxidase and uric acid levels were suppressed [49]. Moreover, GPx in the subset 


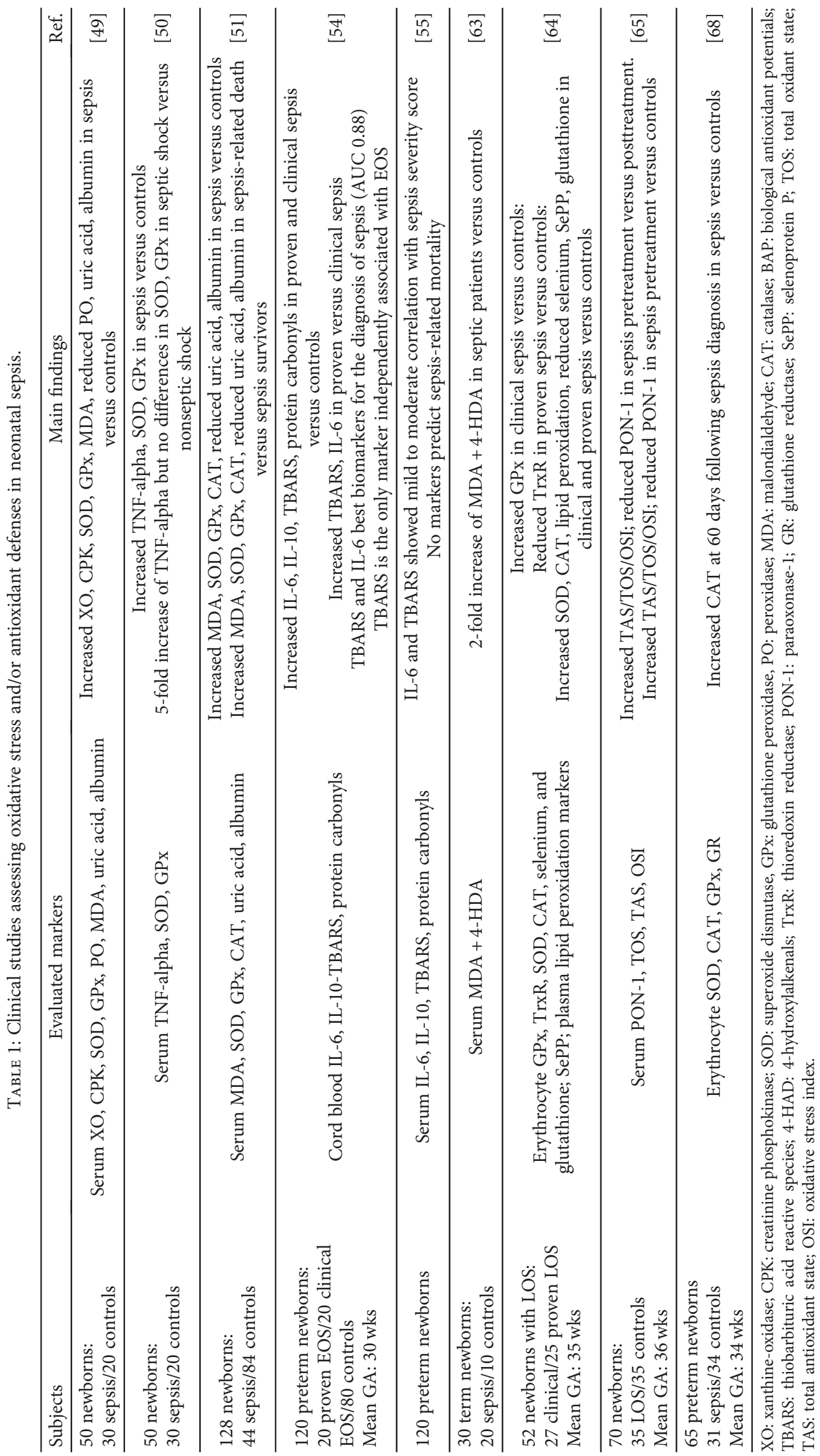


of newborns with septic shock was significantly higher than in patients with sepsis but no septic shock [49], suggesting a preferential hyperactivation of antioxidant pathways related to glutathione during septic shock. In 44 newborns with sepsis, MDA, SOD, GPx, and CAT were significantly increased in comparison to controls, while uric acid and albumin levels were significantly reduced [51], and similar changes were also observed in those newborns who died because of sepsis in comparison to survivors [51].

These data are consistent with the activation of prooxidant pathways and ROS overproduction during sepsis, paralleled by an increased activity of antioxidant defense systems, which, however, cannot cope with increased oxidative burden, resulting in detrimental cellular effects, as demonstrated by increased markers of oxidative damage [49]. In accordance with these observations, in a neonatal sepsis model obtained by cecal ligation and perforation (CLP) in piglets, total hydroperoxide (TH) and biological antioxidant potentials (BAP) were both increased 1 hour after the procedure in comparison to sham animals, and BAP remained significantly higher during the 6-hour study period [52]. The increase of TH and BAP was paralleled by a significant increase of TNF-alpha and IL-6 in septic animals in comparison to controls, and a positive correlation was observed at 1-hour post-CLP between TH and BAP, TH and TNFalpha, and BAPs and IL-6 [52], suggesting mutual interactions between inflammatory pathways and oxidative stress during neonatal sepsis. Consistent with these data, more recently, excessive ROS production was directly demonstrated by DCF fluorescence technique in vital section of renal cortex of newborn rats exposed to LPS [53].

In a cohort of 120 preterm newborns with mean gestational age of 31 weeks, including 20 patients with proven EOS, 20 patients with highly probable EOS, and 80 uninfected controls, oxidative stress and inflammatory markers in cord blood samples were proved to be significantly higher in septic patients versus controls [54]. Particularly, both protein carbonyls, a marker of protein oxidation, and thiobarbituric acid reactive species (TBARS), a marker of lipid peroxidation, were increased along with IL-6 and IL-10 levels in patients with sepsis, both proven or clinically highly probable, in comparison to controls, and in patients with proven sepsis in comparison to controls [54]. Only TBARS and IL-6, but not the other markers, were significantly increased in the group of proven sepsis versus highly probable sepsis [54]. According to ROC curve analysis, TBARS and IL- 6 showed the best performance for the diagnosis of EOS among the studied markers with an area under the curve of 0.88 . Multivariate logistic analysis comparing TBARS and IL- 6 showed that TBARS is a better predictor of EOS and TBARS was the only marker independently associated with EOS [54]. TBARS and IL-6 levels in preterm newborns also showed a mild to moderate correlation with clinical sepsis severity score, although no correlation was demonstrated between these markers and sepsis-related mortality [55]. As some markers of oxidative stress, along with indicators of antioxidant defense, are available as point-of-care test (POCT), the confirmation of a relationship between oxidative stress markers and sepsis severity would be of major relevance in critical care settings. Particularly, available or under development POCTs for oxidative stress and antioxidant status include free oxygen radicals test [56, 57], free oxygen radicals defense test [56, 57], 8-hydroxy-2'-deoxyguanosine [58], 3-nitrotyrosine [59], CuZn SOD [60], BAP, measured as capacity of reduction of ferric to ferrous ions [57], and iridium-reducing assay, particularly sensitive to GSH [61]. Despite at present these POCTs have been studied in the adult population, they would offer several advantages for critically ill newborns, as timely manner stratification of sepsis severity and identification of a patient who would particularly benefit from antioxidant strategies, the need for small blood samples, and the possibility to monitor the response to antioxidant treatment. At present, no relationship has been established between oxidative stress markers and the development of long-term adverse outcomes in septic newborns; however, some biomarkers of inflammation, as S100B, adrenomedullin, and neuron-specific enolase, were proved to be also markers of neonatal brain damage [62]. Moreover, cord blood levels of oxidative stress markers were related to free radical-related diseases, including IVH, in preterm newborns [31], indicating that studies are needed in order to assess whether early markers could predict long-term outcome in septic newborns.

In a small cohort of septic term newborns, pretreatment levels of lipid peroxidation-derived aldehydes, MDA and 4-hydroxylalkenals (4-HDA), were demonstrated to be roughly 2 -folds higher than in healthy controls [63]. In 52 newborns with LOS and mean gestational age of 35-36 weeks, plasma lipid peroxidation markers and protein carbonyls were proved to increase significantly in patients with proven or clinical sepsis in comparison to uninfected controls [64]. The study of erythrocyte selenoenzymes showed increased GPx levels in patients with clinical sepsis and reduced thioredoxin reductase levels in patients with proven sepsis in comparison to controls [64], demonstrating differential regulation of antioxidant selenoenzymes during sepsis. SOD and CAT were increased in septic patients, demonstrating an adaptive antioxidant response to oxidative stress during sepsis, while erythrocyte selenium, erythrocyte glutathione, and selenoprotein $\mathrm{P}$, the main plasma selenoprotein, were markedly decreased in patients with proven or clinical sepsis in comparison to controls, suggesting consumption of selenium-containing antioxidant molecules [64].

According to the available evidence, in neonatal sepsis, both oxidative stress-related pathways and antioxidant defenses appear induced; however, redox unbalance favoring oxidative stress likely occurs, as markers of oxidative damage are increased in comparison to controls $[49,50]$. Concordant with this observation, in 70 newborns with mean gestational age of 36 weeks, total oxidant state (TOS) and total antioxidant state (TAS) were both increased in septic patients in the pretreatment period versus controls and oxidative stress index (OSI), and the percentage ratio of TOS/TAS, was also increased [65], confirming the prevalence of oxidative stress pathways on antioxidant defense. TOS and TAS were also studied to monitor treatment and significantly decreased 
after treatment in septic patients in comparison to pretreatment levels. Moreover, paraoxonase-1 (PON-1), an enzyme located in HDL inhibiting lipoprotein oxidation in LDL [66], which is reduced in adult sepsis [67], appeared significantly lower in septic newborns before treatment in comparison to controls and also to posttreatment levels [65]. In septic patients after treatment, higher TAS levels were observed in comparison to controls, while TOS and PON-1 did not significantly differ, suggesting that compensatory antioxidant defense might continue beyond the initial oxidative burst. In contrast with these findings, in a cohort of preterm newborns with mean gestational age of 34 weeks, no differences in erythrocyte GPx, GR, and CAT were detected between septic patients and controls during the clinical course of sepsis, although in septic patients at 60 days, CAT activity was significantly increased in comparison to controls and GPx activity depressed in comparison to day 0 [68].

Chorioamnionitis is a well-known risk factor for fetal and neonatal infection, especially in preterm newborns, as about $5-17 \%$ of preterm newborns whose mother has chorioamnionitis develop EOS $[69,70]$. In preterm newborns with gestational age $<30$ weeks, oxidative stress markers, as isoprostanes, nonprotein-bound iron, and advanced oxidative protein products were proved to be significantly increased in cord blood of newborns of mothers with histological chorioamnionitis in comparison to the control group [71]. Moreover, a significant positive correlation was found in multivariate analysis adjusted for the main neonatal and perinatal variables between histological chorioamnionitis and cord levels of oxidative stress markers, indicating increased fetal oxidative burden during intra-amniotic infection [71]. Moreover, increased levels of oxidative markers as prolidase, matrix metalloproteinases, TOS, and OSI were demonstrated in vaginal washing fluid of healthy pregnant women with preterm premature rupture of membranes (PPROM) in comparison to controls with intact membranes, while antioxidant parameters, as PON-1 and total antioxidant capacity (TAC), were significantly lower [72]. Moreover, prolidase, matrix metalloproteinases, and oxidativeantioxidant status parameters significantly differed in women with chorioamnionitis in comparison to those without chorioamnionitis in the PPROM group and levels of prolidase, matrix metalloproteinase-13, TOS, TAC, and PON-1 were proved to predict chorioamnionitis in the PPROM group [72]. These results are partially discordant with the observation of measurable amount of oxidative stress markers in amniotic fluid in 183 pregnant women with PPROM but the absence of influence of intra-amniotic infection or histological chorioamnionitis on the levels of oxidative stress and antioxidant biomarkers [73]. Concordantly, intra-amniotic infection, histological chorioamnionitis, and funisitis did not significantly affect cord blood TAC, ferric reducing antioxidant power, TBARS, advanced glycation end products, and markers of oxidative stress in the offspring of 165 pregnancies complicated by PPROM [74]. On a whole, despite increased fetal and oxidative burden could occur as a result of PPROM and chorioamnionitis, although mixed results were reported, at present, no conclusions can be derived regarding its role in neonatal sepsis, as no data on oxidative balance are available for the subset of newborns who develop EOS as a consequence of maternal chorioamnionitis.

2.3. Intestinal Microbiota and Oxidative Stress. The gastrointestinal system was recently demonstrated to take part in the oxidative burst during sepsis in preterm newborns, providing evidence that host-microbiota interactions could be of major importance under septic conditions [75]. Fecal samples of 5 pairs of twins with mean gestational age of 30 weeks, each pair including one septic and one control twin, were used for microbiota analysis and genome-wide expression analysis on exfoliated intestinal cells. Induction of several genes involved in proinflammatory and prooxidant pathways was demonstrated in intestinal cells of septic newborns in comparison to controls, and such genome expression changes were paralleled by microbiota shift towards predominance of Enterobacteria with reduction of Bacteroides and Bifidobacteria, likely resulting from oxidative stress and lowgrade inflammation in the gut mucosa [75]. A significant inverse correlation was observed between Bacteroides and Bifidobacteria and 8 genes involved in oxidative stress, and also further genes involved in TNF-alpha and IL-1beta signaling pathways [75]. These results were in agreement with a previous study of blood genome-wide expression profile in very low birthweight (VLBW) infants, demonstrating overexpression of genes involved in innate immunity and inflammation in septic patients in comparison to controls [76]. These aspects could be of major importance in the population of preterm newborns, who exhibited basal overexpression of genes related to inflammation in the gut in comparison to term newborns, as demonstrated by whole genome sequencing of stool-derived mRNA [77], and overexpressed in septic condition pathways related to IL-1 receptor kinase 2, fibroblast growth factor receptors, gap junctions, and cell division regulators [78]. Moreover, in a preterm pig model of necrotizing enterocolitis (NEC), the study of intestinal proteomics demonstrated that antibiotic treatment induced several beneficial mucosal pathways, including antioxidant ones, as CAT activity was significantly increased in comparison to untreated animals, suggesting that antibiotic treatment during NEC is associated to a more favorable redox profile, shifting towards antioxidant prevalence [79].

Intestinal microbiota has recently become a central component of the sepsis process in preterm newborns as the disruption of physiological intestinal colonization induced by aggressive antibiotic treatment was proved to favor the development of pathogen species and to be associated with adverse outcomes [80, 81]. Early empirical antibiotics administered for more than 5 days, without evidence of positive blood culture, was positively associated to increased risk of NEC and death in a large cohort of ELBW infants [82] and to increased incidence of LOS and of the combined outcome LOS-NEC-death in 365 VLBW infants [83]. It was hypothesized that high levels of circulating proinflammatory and prooxidant mediators observed in septic newborns, through an inflammatory organ cross-talk, may affect gut mucosa gene expression profile, leading to local environment inflammation and oxidative stress that, in 
turn, would affect microbial colonization, favoring pathogen species [75].

As antibiotics are one of the milestones of medical treatment of NEC but inappropriate antibiotic courses are related to adverse outcomes, the optimal antibiotic regimen for patients with NEC is of crucial importance in clinical settings $[84,85]$. Two recent surveys reported high variability among different centers and within single centers in antibiotic treatments for NEC in terms of type and number of antibiotics and duration of treatment $[84,85]$. Despite the most frequently reported regimen was the association of amoxicillin or ampicillin, gentamycin, and metronidazole $[84,85]$ basing on old data [86], the criteria to broaden antibiotic spectrum were variable among practitioners and for surgical patients, the duration of postsurgery antibiotic course was not standardized [85]. Two meta-analyses found insufficient evidence to make specific recommendations on the most appropriate type and duration of antibiotic treatment $[87,88]$; therefore, specifically designed studies should be performed to address the optimal antibiotic regimen for patients with NEC in terms of harm/benefit ratio.

Finally, different antioxidant treatments were suggested to be effective in the prevention of NEC development in preterm newborns. Particularly, oral supplementation with lactoferrin was proved to reduce NEC occurrence in a meta-analysis $[89,90]$, although this evidence had low-tomoderate quality [91] and human recombinant lactoferrin was administered only in one study, while bovine lactoferrin was used in all the others [91]. The beneficial effect of lactoferrin in preserving the gut mucosa integrity is likely related to the position of lactoferrin itself on the mucosal surface, where it contrasts microbial invasion and translocation across the intestinal wall [91]. On the other hand, pentoxifylline administration showed mixed result, and in meta-analysis, did not affect NEC occurrence [92]. However, because of the low quality of evidence, specific trials investigating pentoxifylline treatment for NEC prevention and treatment are advocated [92]. N-Acetylcysteine administration in a rat model of NEC reduced gut oxidative stress damage measured as MDA, gut abnormalities, and intestinal levels of TNFalpha, while was proved to increase local activity of antioxidant enzymes [93]. Finally, also melatonin was hypothesized to confer protection against NEC development, due to its pleiotropic and multiorgan antioxidant activities [94]; however, its potential usefulness in NEC prevention remains at present to be assessed by clinical trials.

\section{Antioxidant Strategies in Neonatal Sepsis}

Basing on evidence of increased oxidative burden in neonatal sepsis, therapeutic strategies targeting proinflammatory and prooxidant pathways would be expected to be beneficial; however, despite promising results in cellular and animal models, evidence from clinical trials is still limited. In the neonatal populations, antioxidant treatments investigated during sepsis include both direct antioxidant administration and pharmacologic inhibition of prooxidant pathways.

Melatonin demonstrated pleiotropic antiapoptotic, antioxidant, and anti-inflammatory effects in vitro and in vivo, as direct scavenging activity against ROS and other oxidizing agents and stimulation of antioxidant enzymes, as CAT, SOD, GPx, GR, and gamma-glutamylcysteine synthase, the rate-limiting enzyme in glutathione synthesis [95]. Interestingly, melatonin accumulates within the mitochondria $[95,96]$; therefore, it would possibly target the local excessive ROS production, which is typical of dysfunctional mitochondria during sepsis $[8,27]$. In preterm newborns, melatonin was demonstrated effective in reducing oxidative stress markers and inflammatory mediators in RDS and perinatal asphyxia [97, 98]. In a small cohort of septic term newborns, oral melatonin treatment within the first 12 hours from diagnosis ( 2 doses, $10 \mathrm{mg} / \mathrm{kg}$ each, administered at 1 -hour interval) significantly reduced lipid peroxidation markers, $\mathrm{MDA}+4-\mathrm{HDA}$, at 1 and 4 hours after treatment [63] (Table 2). Melatonin-treated infants also showed a significant reduction in white blood cell count, absolute neutrophil count, and CRP 24 hours after treatment, while at the same time untreated septic infants presented stable white blood cell count and neutrophil count and increased CRP levels. Moreover, while 3 of 10 septic untreated infants died, no cases of death were observed in the melatonin-treated group [63]. These encouraging results are consistent with a favorable suppression of prooxidant and proinflammatory pathways induced by melatonin treatment in neonatal sepsis, occurring as early as 1 hour after oral administration [63]. Concordantly, in a recent nonrandomized trial including 40 septic newborns treated with antibiotics and melatonin $(20 \mathrm{mg} / \mathrm{kg}$, single dose) or antibiotics alone, melatonin treatment was associated with a significantly stronger reduction of CRP levels and improvement of clinical parameters in comparison to antibiotic treatment alone [99] and it was also shown to improve clinical sepsis score in comparison to antibiotic treatment alone in a cohort of 50 septic newborns [100]. These data are also concordant with the observation of beneficial effect of melatonin in newborns in the postsurgery period, showing reduced nitrite-nitrate and proinflammatory cytokines levels following melatonin administration in comparison to untreated surgical newborns [101]. Interestingly, higher melatonin levels were demonstrated in septic newborns with LOS in comparison to uninfected controls [102], suggesting that melatonin endogenous production might be upregulated during sepsis, taking part in antioxidant defense. Basing on these favorable preliminary data, randomized control trials are warranted to assess efficacy and safety of melatonin as an adjunct treatment in neonatal sepsis [103].

Promising results in antioxidant treatment for neonatal sepsis were obtained with the administration of pentoxifylline, which exerts several antioxidant and antiinflammatory activities, as reduced glutathione level restoration, mitochondrial viability maintenance, inhibition of TNF-alpha production, preservation of proper endothelial function and of proper coagulation activity, and prevention of gastrointestinal vasoconstriction [104]. In a randomized controlled trial including 120 newborns with LOS and mean gestational age of 30 weeks, pentoxifylline administration $(5 \mathrm{mg} / \mathrm{kg} / \mathrm{h}$ i.v. for 6 hours for 6 days) was associated with reduced TNF-alpha and CRP levels, reduced need for vasopressor, shorter duration of respiratory support and 
TABLE 2: Main evidence from clinical studies on melatonin and pentoxifylline treatment in neonatal sepsis.

\begin{tabular}{|c|c|c|c|}
\hline Enrolled population & Interventional procedure & Outcomes & Ref. \\
\hline \multicolumn{4}{|l|}{ Melatonin } \\
\hline $\begin{array}{l}30 \text { newborns: } \\
10 \text { sepsis/10 sepsis and melatonin } \\
\text { treatment } / 10 \text { controls }\end{array}$ & $\begin{array}{l}\text { Melatonin, } 20 \mathrm{mg} / \mathrm{kg} \text { orally within } 12 \text { hours } \\
\text { of sepsis diagnosis }(2 \text { doses, } 10 \mathrm{mg} / \mathrm{kg} \text { each, } \\
\text { separated by } 1 \text {-hour interval) }\end{array}$ & $\begin{array}{c}\text { Reduced MDA + 4-HDA at } 1 \text { and } 4 \text { hours after } \\
\text { treatment in septic treated versus septic } \\
\text { untreated infants } \\
\text { Reduced WBC count, ANC, CRP } 24 \text { hours after } \\
\text { treatment in septic treated versus septic } \\
\text { untreated infants }\end{array}$ & {$[63]$} \\
\hline $\begin{array}{l}40 \text { newborns: } \\
20 \text { sepsis } / 20 \text { sepsis and } \\
\text { melatonin treatment }\end{array}$ & Melatonin, $20 \mathrm{mg} / \mathrm{kg}$ orally, single dose & $\begin{array}{c}\text { Reduced CRP and better clinical improvement at } 24 \\
\text { and } 72 \text { hours after treatment in treated versus } \\
\text { untreated infants }\end{array}$ & [99] \\
\hline $\begin{array}{l}50 \text { newborns: } \\
25 \text { sepsis } / 25 \text { sepsis and } \\
\text { melatonin treatment }\end{array}$ & Melatonin, $20 \mathrm{mg} / \mathrm{kg}$ orally, single dose & $\begin{array}{l}\text { Reduced sepsis score at } 24 \text { and } 48 \text { hours after } \\
\text { treatment in treated versus untreated infants }\end{array}$ & {$[100]$} \\
\hline \multicolumn{4}{|l|}{ Pentoxifylline } \\
\hline $\begin{array}{l}120 \text { newborns: } \\
60 \text { LOS/60 LOS and } \\
\text { pentoxifylline treatment }\end{array}$ & $\begin{array}{c}\text { Pentoxifylline, } 5 \mathrm{mg} / \mathrm{kg} / \mathrm{h} \text { IV for } 6 \text { hours } \\
\text { for } 6 \text { days }\end{array}$ & $\begin{array}{l}\text { Reduced TNF-alpha, vasopressor need, duration of } \\
\text { respiratory support, duration of antibiotics, hospital } \\
\text { stay, incidence of DIC, and thrombocytopenia in } \\
\text { treated versus untreated infants } \\
\text { No differences in mortality } \\
\end{array}$ & {$[105]$} \\
\hline $\begin{array}{l}\text { Meta-analysis of } 6 \text { randomized } \\
\text { or quasi-randomized trials; } \\
416 \text { newborns }\end{array}$ & $\begin{array}{l}\text { Pentoxifylline, continuous IV infusion, } \\
\text { different dosing regimens }\end{array}$ & $\begin{array}{l}\text { Reduced all-cause mortality, reduced hospital stay } \\
\text { in septic treated versus untreated septic infants } \\
\text { Reduced mortality in the subgroup of preterm } \\
\text { newborns, proven sepsis, and Gram-negative sepsis } \\
\text { in septic treated versus untreated septic infants }\end{array}$ & {$[106]$} \\
\hline
\end{tabular}

MAD: malondialdehyde; 4-HDA: 4-hydroxylalkenals; WBC: white blood cell; ANC: absolute neutrophil count; CRP: C-reactive protein; DIC: disseminated intravascular coagulopathy; LOS: late-onset sepsis.

antibiotic treatment, shorter hospital stay, lower incidence of disseminated intravascular coagulopathy, metabolic acidosis, and thrombocytopenia [105] (Table 2). However, no differences were observed in mortality and short-term morbidity between pentoxifylline-treated and untreated septic newborns $[105,106]$. In a meta-analysis including 6 small studies, pentoxifylline administration in septic newborns was proved effective in reducing all-cause mortality and the length of hospital stay, and subgroup analysis demonstrated significantly reduced mortality in preterm infants, in infants with proven sepsis, and in infants with Gram-negative sepsis [92], leading to the conclusion that pentoxifylline may represent a beneficial adjunct treatment in neonatal sepsis, although larger trials are needed in order to define pentoxifylline efficacy and the safety profile. Interestingly, in vitro pentoxifylline was recently proved to exert more powerful anti-inflammatory effects in newborns than in adults [107]. In cord blood and adult blood stimulated with LPS, pentoxifylline treatment suppressed TLR-mediated cytokines levels, as TNF-alpha and IL-1beta, in a dose-dependent manner and this effect was more pronounced in cord blood in comparison to adult blood [107], suggesting that pentoxifylline adjunct treatment could be particularly beneficial in the neonatal population.

Lactoferrin, a normal component of human milk, is an anti-infective and antioxidant agent, acting through iron sequestration and direct detrimental effect on pathogen cell membranes [108]. In a randomized controlled trial including 472 VLBW infants who were randomized to lactoferrin alone or lactoferrin and probiotics or placebo, the supplementation with lactoferrin alone or in combination with probiotics significantly reduced the incidence of LOS, both fungal and bacterial, in comparison to placebo [109]. Moreover, a recent meta-analysis including 6 randomized controlled trials showed that lactoferrin supplementation to enteral feeds in preterm newborns, alone or in combination with probiotics, reduced the incidence of LOS and NEC stage II or III, although overall mortality was not affected [89]. However, at present, no evidence are available on the possible beneficial effect of lactoferrin administration during neonatal sepsis; therefore, further studies are needed to assess whether lactoferrin could be beneficial not only as a preventive measure but also as an adjunct treatment for neonatal sepsis and also to establish the optimal dosing regimen. Interestingly, in 15 preterm newborns, serum lactoferrin levels were significantly lower in patients with proven sepsis in comparison to those with clinical sepsis and were positively correlated with white blood cell count or absolute neutrophil count, suggesting that the lowest lactoferrin observed in more immature infants is likely related to suboptimal white cell activity and that lactoferrin supplementation could be particularly effective in this population [110].

Vitamin E, which acts primarily as circulating direct antioxidant, has been extensively investigated for the prevention of prematurity-related mortality and morbidity and was proved effective in reducing the incidence of intracranial bleeding and retinopathy of prematurity in the subset of VLBW infants in a meta-analysis including 26 randomized 
TABLE 3: Animal studies of novel antioxidant treatments in neonatal sepsis.

\begin{tabular}{|c|c|c|c|}
\hline Model & Interventional procedures & Outcomes & Ref. \\
\hline \multicolumn{4}{|c|}{ Edaravone } \\
\hline Piglets & $\begin{array}{l}\text { CLP alone or CLP and IV continuous } \\
\text { edaravone infusion }\end{array}$ & $\begin{array}{c}\text { Reduced TH at } 1 \text { hour after CLP, reduced nitrite-nitrate at } 3 \text { and } 6 \text { hours, reduced } \\
\text { HMGB-1, delayed TNF-alpha surge, increased mean arterial pressure, reduced } \\
\text { heart rate, longer survival time in treated versus untreated animals }\end{array}$ & {$[117]$} \\
\hline Piglets & $\begin{array}{l}\text { CLP alone or CLP and IV continuous } \\
\text { edaravone infusion }\end{array}$ & $\begin{array}{c}\text { Reduced pulmonary hypertension in treated versus untreated animals } \\
\text { Mean pulmonary artery pressure/mean systemic arterial pressure ratio positively } \\
\text { related to TNF-alpha levels }\end{array}$ & {$[118]$} \\
\hline \multicolumn{4}{|c|}{ Endothelin-1 receptor antagonist } \\
\hline Piglets & $\begin{array}{l}\text { CLP alone or CLP and IV continuous } \\
\text { ETR-P1/fl infusion or controls }\end{array}$ & $\begin{array}{l}\text { Reduced nitrite-nitrate, TNF-alpha, HMBG-1, reduced pulmonary hypertension } \\
\text { in CLP-treated animals versus CLP alone }\end{array}$ & {$[123]$} \\
\hline Piglets & $\begin{array}{l}\text { CLP alone or CLP and IV continuous } \\
\text { ETR-P1/fl infusion or controls }\end{array}$ & Reduced TH, OSI, IL- 6 at 3 and 6 hours post-LP & [124] \\
\hline
\end{tabular}

CLP: cecal ligation perforation; TH: total hydroperoxide; OSI: oxidative stress index; HMGB-1: high mobility group box 1.

controlled trials [111]. However, vitamin E supplementation was associated with increased risk of sepsis both in the case of intravenous and nonintravenous administration and serum tocopherol levels higher than the cut-off of $3.5 \mathrm{mg} / \mathrm{dL}$ were positively associated with increased risk of sepsis [111], leading to the conclusion that routine vitamin $\mathrm{E}$ supplementation in preterm newborns cannot be recommended. In a recent randomized open-label study including 65 preterm newborns with mean gestational age of 34 weeks, vitamin E supplementation reduced GPx activity at 30 days in septic newborns in comparison to untreated septic newborn although it also mitigated the reduction of GPx observed in septic patients 60 days after sepsis onset [68]. Moreover, vitamin E supplementation suppressed GR activity in treated septic patients, while increased GPx activity in controls in comparison to untreated controls [68]. The combination of direct scavenging effect of vitamin $\mathrm{E}$ with increased GPx activity would result in enhanced $\mathrm{H}_{2} \mathrm{O}_{2}$ removal with a reduction in efficiency of circulating pathogen discharge and therefore would explain the increased risk of sepsis observed in vitamin Esupplemented newborns $[68,111]$.

Other antioxidant measures with potential efficacy in neonatal sepsis that have been investigated in clinical settings include selenium [112] and zinc supplementation [113], and treatment with ibuprofen [114].

Edaravone (3-methyl-1-phenyl-pyrazolin-5-one), a free radical scavenger introduced in the latest years in experimental settings, exerts multiple antioxidant effects, as hydroxyl radical scavenging, suppression of hydroxyl-dependent lipid peroxidation, and electron donation to ROS [115], leading to beneficial effects in animal models of neonatal hypoxicischemic encephalopathy [116]. In a piglet model of neonatal sepsis, edaravone was demonstrated to reduce TH levels 1 hour after CLP and nitrite-nitrate levels at 3 and 6 hours in comparison to septic untreated animals, indicating favorable antioxidant effects [117] (Table 3). These changes were paralleled by clinical improvement of septic animals, as demonstrated by higher cardiac output and mean arterial pressure, lower heart rate, and longer survival time in treated versus untreated animals, suggesting possible beneficial effects of edaravone on sepsis clinical course in the newborns [117]. Furthermore, edaravone delayed TNF-alpha surge in treated animals and also prevented the increase of high mobility group box 1 (HMGB-1), a nuclear transcription factor involved in the systemic inflammatory response [117]. In the same animal models, edaravone was also proved effective in reducing sepsis-related pulmonary hypertension and the ratio between mean pulmonary and systemic arterial pressure was positively related to TNF-alpha levels, suggesting that edaravone may exert suppressive action on TNF-alpha release [118]. In a small cohort of pediatric patients with cerebral infarction, edaravone was recently associated with improved neurological outcome without significant adverse effects [119].

The endothelin system is well known to be involved in sepsis, as endothelin-1 (ET-1) induces activation of NF- $\kappa$ Bmediated proinflammatory pathways and expression of adhesion molecules [120] and ET-1 levels appear increased in septic newborns, particularly in case of pulmonary hypertension [121, 122]. The infusion of endothelin receptor antagonist ETR-P1/fl was proved effective in reducing serum nitrite and nitrate, TNF-alpha, and HMBG-1 in a piglet model of neonatal sepsis and also in reducing pulmonary hypertension and increasing mean arterial pressure and survival time [123] (Table 3). In accordance with this study, in the same animal model, treatment with ETR-P1/fl reduced TH, OSI (calculated as total hydroperoxide/biological antioxidant potentials), and IL- 6 at 3 and 6 hours after CLP, indicating attenuation of prooxidant and proinflammatory insult [124]. At present, endothelin receptor antagonists have never been investigated in clinical settings in the newborn.

As dysfunctional mitochondria are the key factor of organ impairment during sepsis $[8,28]$, mitochondrialtargeted antioxidant treatment has been studied in preclinical models of adult sepsis [125]. In order to achieve antioxidant protection of mitochondria, potential useful strategies include the administration of ROS scavengers, which specifically target the mitochondria and act where needed within the mitochondria, or the induction of endogenous mitochondrial antioxidant system [125]. Particularly, the main studied agents are obtained by conjugation of antioxidant molecules 
to lipophilic cations that accumulate in the mitochondria, driven by mitochondrial membrane potentials, as MitoQ, containing ubiquinone antioxidant moiety, or by the conjugation of fragment of antibiotic with the stable nitroxide radical TEMPOL, that is able to accept electrons from unstable ROS, to dismute superoxide anion, and to exert catalase-like activity [125]. Other strategies under investigation include the administration of small synthetic peptides (SS peptides) with scavenger activity, which selectively concentrate in the mitochondria, and potentiation of endogenous mitochondrial antioxidant defenses by the administration of $\mathrm{N}$-acetyl-1-cysteine, which accumulates in the mitochondria and increases local glutathione availability or by genetic approaches, as adenoviral transfection with MnSOD [125]. At present, none of these strategies has been studied in models of neonatal sepsis; therefore, mitochondrial-targeted antioxidant treatment could represent a potential future line of research in the field of neonatal sepsis.

\section{Conclusions}

Oxidative stress, along with proinflammatory pathways, was demonstrated to play a major role in neonatal sepsis both in vitro and in vivo. However, few evidences are available at present on the clinical usefulness of adjunct antioxidant treatment in neonatal sepsis.

Some relevant limitations of the studies investigating oxidative stress and antioxidant treatments in neonatal sepsis may partially limit the quality of the available evidence. Most of the studies assessing antioxidant enzyme activity in neonatal sepsis were based on serum measurements that could be influenced by hemolysis processes and in fact provided partially different evidences in comparison to observations based on erythrocyte level measurements [68]. Moreover, data obtained from animal studies on oxidative stress markers or antioxidant treatments in neonatal sepsis may not strictly reflect the clinical conditions of septic newborns, as in experimental settings, the animal models are challenged with high levels of LPS or bacteria, which is often not the case in clinical practice $[52,53,117,118,123,124]$. As regard to clinical observations, not all of the studies reported rigorous inclusion criteria, defining whether both EOS and LOS or only one of the two categories is included; therefore, conclusions derived from these studies could be misleading as redox pathophysiology of EOS and LOS could be partially different. Moreover, while some studies included only culture-proven sepsis, others included both proven and clinical sepsis, and others did not specify this aspect. However, due to the fact that several nonsepsis-related perinatal variables could affect oxidative stress in newborns, only data coming from proven sepsis patients should be considered fully reliable, while those coming from clinical sepsis patients could merely reflect the effect of different conditions activating oxidative stress pathways. Finally, clinical studies investigating the usefulness of antioxidant treatments in neonatal sepsis often lack strict randomization, leading to evidences that, although promising, need to be confirmed by properly designed studies.

Despite several limitations, available evidence suggests that oxidative stress processes are activated during neonatal sepsis, posing the basis for the potential clinical usefulness of antioxidants as an adjunct strategy for the treatment of septic newborns. Antioxidants, in fact, would counterbalance the detrimental prooxidant cycle in newborn sepsis, which, once initiated, proceeds independently from the pathogens themselves and thus is not affected by antibiotic treatment alone. Further studies are needed to identify useful agents and to standardize antioxidant treatment in neonatal sepsis.

\section{Conflicts of Interest}

The authors declare that there is no conflict of interest regarding the publication of this paper.

\section{References}

[1] L. Liu, S. Oza, D. Hogan et al., "Global, regional, and national causes of under-5 mortality in 2000-15: an updated systematic analysis with implications for the sustainable development goals," The Lancet, vol. 388, no. 10063, pp. 3027-3035, 2016.

[2] R. G. Greenberg, S. Kandefer, B. T. Do et al., "Late-onset sepsis in extremely premature infants: 2000-2011," The Pediatric Infectious Disease Journal, vol. 36, no. 8, pp. 774-779, 2017.

[3] B. J. Stoll, N. I. Hansen, E. F. Bell et al., "Neonatal outcomes of extremely preterm infants from the NICHD Neonatal Research Network," Pediatrics, vol. 126, no. 3, pp. 443-456, 2010.

[4] J. L. Wynn, H. R. Wong, T. P. Shanley, M. J. Bizzarro, L. Saiman, and R. A. Polin, "Time for a neonatal-specific consensus definition for sepsis," Pediatric Critical Care Medicine, vol. 15, no. 6, pp. 523-528, 2014.

[5] B. Goldstein, B. Giroir, A. Randolph, and International Consensus Conference on Pediatric Sepsis, "International pediatric sepsis consensus conference: definitions for sepsis and organ dysfunction in pediatrics," Pediatric Critical Care Medicine, vol. 6, no. 1, pp. 2-8, 2005.

[6] M. Bajcetic, S. Spasic, and I. Spasojevic, "Redox therapy in neonatal sepsis: reasons, targets, strategy, and agents," Shock, vol. 42, no. 3, pp. 179-184, 2014.

[7] R. S. Hotchkiss and I. E. Karl, "The pathophysiology and treatment of sepsis," The New England Journal of Medicine, vol. 348, no. 2, pp. 138-150, 2003.

[8] M. E. Andrades, A. Morina, S. Spasić, and I. Spasojević, "Bench-to-bedside review: sepsis - from the redox point of view," Critical Care, vol. 15, no. 5, p. 230, 2011.

[9] I. Spasojević, B. Obradović, and S. Spasić, "Bench-to-bedside review: neonatal sepsis - redox processes in pathogenesis," Critical Care, vol. 16, no. 3, p. 221, 2012.

[10] E. Volante, S. Moretti, F. Pisani, and G. Bevilacqua, "Early diagnosis of bacterial infection in the neonate," The Journal of Maternal-Fetal \& Neonatal Medicine, vol. 16, no. 2, pp. 13-16, 2004.

[11] P. C. Ng and H. S. Lam, "Biomarkers for late-onset neonatal sepsis: cytokines and beyond," Clinics in Perinatology, vol. 37, no. 3, pp. 599-610, 2010.

[12] Q. Ye, L. Z. Du, W. X. Shao, and S. Q. Shang, "Utility of cytokines to predict neonatal sepsis," Pediatric Research, vol. 81, no. 4, pp. 616-621, 2017. 
[13] K. S. Khaertynov, S. V. Boichuk, S. F. Khaiboullina et al., "Comparative assessment of cytokine pattern in early and late onset of neonatal sepsis," Journal of Immunology Research, vol. 2017, Article ID 8601063, 8 pages, 2017.

[14] E. Segura-Cervantes, J. Mancilla-Ramírez, J. GonzálezCanudas et al., "Inflammatory response in preterm and very preterm newborns with sepsis," Mediators of Inflammation, vol. 2016, Article ID 6740827, 8 pages, 2016.

[15] L. Koch, D. Frommhold, K. Buschmann, N. Kuss, J. Poeschl, and P. Ruef, "LPS- and LTA-induced expression of IL-6 and TNF- $\alpha$ in neonatal and adult blood: role of MAPKs and NF- $\kappa \mathrm{B}, "$ Mediators of Inflammation, vol. 2014, Article ID 283126, 8 pages, 2014.

[16] L. Koch, B. Fritzsching, D. Frommhold, and J. Poeschl, "Lipopolysaccharide-induced expression of Th1/Th2 cytokines in whole neonatal cord and adult blood: role of nuclear factor-kappa B and p38 MAPK," Neonatology, vol. 99, no. 2, pp. 140-145, 2011.

[17] S. Kenzel, G. Mancuso, R. Malley, G. Teti, D. T. Golenbock, and P. Henneke, "c-Jun kinase is a critical signaling molecule in a neonatal model of group B streptococcal sepsis," The Journal of Immunology, vol. 176, no. 5, pp. 3181-3188, 2006.

[18] K. Upadhyay, J. E. Park, T. W. Yoon et al., "Group B streptococci induce proinflammatory responses via a protein kinase D1-dependent pathway," The Journal of Immunology, vol. 198, no. 11, pp. 4448-4457, 2017.

[19] T. Peng, X. Lu, and Q. Feng, "NADH oxidase signaling induces cyclooxygenase- 2 expression during lipopolysaccharide stimulation in cardiomyocytes," The FASEB Journal, vol. 19, no. 2, pp. 293-295, 2005.

[20] H. L. Menden, S. Xia, S. M. Mabry, A. Navarro, M. F. Nyp, and V. Sampath, "Nicotinamide adenine dinucleotide phosphate oxidase 2 regulates LPS-induced inflammation and alveolar remodeling in the developing lung," American Journal of Respiratory Cell and Molecular Biology, vol. 55, no. 6, pp. 767-778, 2016.

[21] J. P. Kinsella, A. Greenough, and S. H. Abman, "Bronchopulmonary dysplasia," The Lancet, vol. 367, no. 9520, pp. 1421-1431, 2006.

[22] J. Figueras-Aloy, L. Gómez, J. M. Rodríguez-Miguélez et al., "Plasma nitrite/nitrate and endothelin-1 concentrations in neonatal sepsis," Acta Paediatrica, vol. 92, no. 5, pp. 582587, 2003.

[23] D. Marom, Y. Yuhas, L. Sirota, G. Livni, and S. Ashkenazi, "Nitric oxide levels in preterm and term infants and in premature infants with bacteremia," Biology of the Neonate, vol. 86, no. 3, pp. 160-164, 2004.

[24] V. Sugitharini, A. Prema, and E. Berla Thangam, "Inflammatory mediators of systemic inflammation in neonatal sepsis," Inflammation Research, vol. 62, no. 12, pp. 1025-1034, 2013.

[25] R. Mittal, I. Gonzalez-Gomez, K. A. Goth, and N. V. Prasadarao, "Inhibition of inducible nitric oxide controls pathogen load and brain damage by enhancing phagocytosis of Escherichia coli $\mathrm{K} 1$ in neonatal meningitis," The American Journal of Pathology, vol. 176, no. 3, pp. 12921305, 2010.

[26] R. Hussain, I. Oliynyk, G. M. Roomans, and M. Björkqvist, "Modulation of ENaC, CFTR, and iNOS expression in bronchial epithelial cells after stimulation with Staphylococcus epidermidis (94B080) and Staphylococcus aureus (90B083)," APMIS, vol. 121, no. 9, pp. 814-826, 2013.
[27] D. W. Park and J. W. Zmijewski, "Mitochondrial dysfunction and immune cell metabolism in sepsis," Infection \& Chemotherapy, vol. 49, no. 1, pp. 10-21, 2017.

[28] N. Arulkumaran, C. S. Deutschman, M. R. Pinsky et al., "Mitochondrial function in sepsis," Shock, vol. 45, no. 3, pp. 271-281, 2016.

[29] K. Fukumoto, A. Pierro, L. Spitz, and S. Eaton, "Differential effects of neonatal endotoxemia on heart and kidney carnitine palmitoyl transferase I," Journal of Pediatric Surgery, vol. 37, no. 5, pp. 723-726, 2002.

[30] G. Buonocore, S. Perrone, and M. L. Tataranno, "Oxygen toxicity: chemistry and biology of reactive oxygen species," Seminars in Fetal and Neonatal Medicine, vol. 15, no. 4, pp. 186-190, 2010.

[31] S. Perrone, M. L. Tataranno, S. Negro et al., "Early identification of the risk for free radical-related diseases in preterm newborns," Early Human Development, vol. 86, no. 4, pp. 241-244, 2010.

[32] S. Perrone, S. Negro, M. L. Tataranno, and G. Buonocore, "Oxidative stress and antioxidant strategies in newborns," The Journal of Maternal-Fetal \& Neonatal Medicine, vol. 23, Supplement 3, pp. 63-65, 2010.

[33] L. Frank and I. R. S. Sosenko, "Failure of premature rabbits to increase antioxidant enzymes during hyperoxic exposure: increased susceptibility to pulmonary oxygen toxicity compared with term rabbits," Pediatric Research, vol. 29, no. 3, pp. 292-296, 1991.

[34] R. L. Morton, K. C. Das, X. Guo, D. N. Iklé, and C. W. White, "Effect of oxygen on lung superoxide dismutase activities in premature baboons with bronchopulmonary dysplasia," American Journal of Physiology-Lung Cellular and Molecular Physiology, vol. 276, no. 1, pp. L64-L74, 1999.

[35] S. Lurie, Z. Matas, M. Boaz, A. Fux, A. Golan, and O. Sadan, "Different degrees of fetal oxidative stress in elective and emergent cesarean section," Neonatology, vol. 92, no. 2, pp. 111-115, 2007.

[36] M. Vento, M. Asensi, J. Sastre, A. Lloret, F. García-Sala, and J. Viña, "Oxidative stress in asphyxiated term infants resuscitated with $100 \%$ oxygen," The Journal of Pediatrics, vol. 142, no. 3, pp. 240-246, 2003.

[37] B. J. Stoll, N. I. Hansen, E. F. Bell et al., "Trends in care practices, morbidity, and mortality of extremely preterm neonates, 1993-2012," JAMA, vol. 314, no. 10, pp. 10391051, 2015.

[38] E. D. Crouser, "Mitochondrial dysfunction in septic shock and multiple organ dysfunction syndrome," Mitochondrion, vol. 4, no. 5-6, pp. 729-741, 2004.

[39] V. Stoka, V. Turk, and D. E. Bredesen, "Differential regulation of the intrinsic pathway of apoptosis in brain and liver during ageing," FEBS Letters, vol. 580, no. 15, pp. 37393745, 2006.

[40] P. S. McQuillen, R. A. Sheldon, C. J. Shatz, and D. M. Ferriero, "Selective vulnerability of subplate neurons after early neonatal hypoxia-ischemia," The Journal of Neuroscience, vol. 23, no. 8, pp. 3308-3315, 2003.

[41] J. J. Volpe, "Neurobiology of periventricular leukomalacia in the premature infant," Pediatric Research, vol. 50, no. 5, pp. 553-562, 2001.

[42] B. A. Barres, I. K. Hart, H. S. R. Coles et al., "Cell death and control of cell survival in the oligodendrocyte lineage," Cell, vol. 70, no. 1, pp. 31-46, 1992. 
[43] C. Poggi and C. Dani, "Antioxidant strategies and respiratory disease of the preterm newborn: an update," Oxidative Medicine and Cellular Longevity, vol. 2014, Article ID 721043, 10 pages, 2014.

[44] H. P. Lukkarinen, J. Laine, and P. O. Kääpä, “Lung epithelial cells undergo apoptosis in neonatal respiratory distress syndrome," Pediatric Research, vol. 53, no. 2, pp. 254-259, 2003.

[45] B. Hargitai, V. Szabó, J. Hajdú et al., “Apoptosis in various organs of preterm infants: histopathologic study of lung, kidney, liver, and brain of ventilated infants," Pediatric Research, vol. 50, no. 1, pp. 110-114, 2001.

[46] R. G. Garrett-Cox, G. Stefanutti, C. Booth, N. J. Klein, A. Pierro, and S. Eaton, "Glutamine decreases inflammation in infant rat endotoxemia," Journal of Pediatric Surgery, vol. 44, no. 3, pp. 523-529, 2009.

[47] M. A. Markley, A. Pierro, and S. Eaton, "Hepatocyte mitochondrial metabolism is inhibited in neonatal rat endotoxaemia: effects of glutamine," Clinical Science, vol. 102, no. 3, pp. 337-344, 2002.

[48] T. Honzik, L. Wenchich, M. Böhm et al., "Activities of respiratory chain complexes and pyruvate dehydrogenase in isolated muscle mitochondria in premature neonates," Early Human Development, vol. 84, no. 4, pp. 269-276, 2008.

[49] S. Batra, R. Kumar, Seema, A. K. Kapoor, and G. Ray, "Alterations in antioxidant status during neonatal sepsis," Annals of Tropical Paediatrics, vol. 20, no. 1, pp. 27-33, 2000.

[50] Seema, R. Kumar, R. N. Mandal et al., "Serum TNF-alpha and free radical scavengers in neonatal septicemia," The Indian Journal of Pediatrics, vol. 66, no. 4, pp. 511-516, 1999.

[51] K. Kapoor, S. Basu, B. K. Das, and B. D. Bhatia, "Lipid peroxidation and antioxidants in neonatal septicemia," Journal of Tropical Pediatrics, vol. 52, no. 5, pp. 372-375, 2006.

[52] H. Kakita, M. H. Hussein, G. A. Daoud et al., "Total hydroperoxide and biological antioxidant potentials in a neonatal sepsis model," Pediatric Research, vol. 60, no. 6, pp. 675679, 2006.

[53] E. Y. Plotnikov, T. A. Pavlenko, I. B. Pevzner et al., “The role of oxidative stress in acute renal injury of newborn rats exposed to hypoxia and endotoxin," The FEBS Journal, vol. 284, no. 18, pp. 3069-3078, 2017.

[54] A. C. Cancelier, F. Petronilho, A. Reinke et al., "Inflammatory and oxidative parameters in cord blood as diagnostic of earlyonset neonatal sepsis: a case-control study," Pediatric Critical Care Medicine, vol. 10, no. 4, pp. 467-471, 2009.

[55] T. A. Valerio, A. C. Cancelier, L. Constantino, F. Petronilho, C. Ritter, and F. Dal-Pizzol, "Inflammatory and oxidative cord blood parameters as predictors of neonatal sepsis severity," Revista Brasileira de Terapia Intensiva, vol. 24, no. 1, pp. 30-34, 2012.

[56] B. Palmieri and V. Sblendorio, "Oxidative stress tests: overview on reliability and use. Part II," European Review for Medical and Pharmacological Sciences, vol. 11, no. 6, pp. 383-399, 2007.

[57] J. S. Nam and C. W. Ahn, "Oxidative stress, point-of-care test, and metabolic syndrome," The Korean Journal of Internal Medicine, vol. 29, no. 1, pp. 20-22, 2014.

[58] G. V. Martins, A. P. M. Tavares, E. Fortunato, and M. G. F. Sales, "Paper-based sensing device for electrochemical detection of oxidative stress biomarker 8-hydroxy-2'-deoxyguanosine (8-OHdG) in point-of-care," Scientific Reports, vol. 7, no. 1, article 14558, 2017.
[59] E. Roy, S. Patra, R. Madhuri, and P. K. Sharma, "Developing electrochemical sensor for point-of-care diagnostics of oxidative stress marker using imprinted bimetallic Fe/Pd nanoparticle," Talanta, vol. 132, pp. 406-415, 2015.

[60] P. Santharaman, M. Das, S. K. Singh et al., "Label-free electrochemical immunosensor for the rapid and sensitive detection of the oxidative stress marker superoxide dismutase 1 at the point-of-care," Sensors and Actuators B: Chemical, vol. 236, pp. 546-553, 2016.

[61] E. Kim, T. E. Winkler, C. Kitchen et al., "Redox probing for chemical information of oxidative stress," Analytical Chemistry, vol. 89, no. 3, pp. 1583-1592, 2017.

[62] I. Bersani, C. Auriti, M. P. Ronchetti, G. Prencipe, D. Gazzolo, and A. Dotta, "Use of early biomarkers in neonatal brain damage and sepsis: state of the art and future perspectives," BioMed Research International, vol. 2015, Article ID 253520, 10 pages, 2015.

[63] E. Gitto, M. Karbownik, R. J. Reiter et al., "Effects of melatonin treatment in septic newborns," Pediatric Research, vol. 50, no. 6, pp. 756-760, 2001.

[64] A. Asci, O. Surmeli-Onay, P. Erkekoglu, S. Yigit, M. Yurdakok, and B. Kocer-Gumusel, "Oxidant and antioxidant status in neonatal proven and clinical sepsis according to selenium status," Pediatrics International, vol. 57, no. 6, pp. 11311137, 2015.

[65] A. Annagür, R. Örs, H. Altunhan et al., "Total antioxidant and total oxidant states, and serum paraoxonase- 1 in neonatal sepsis," Pediatrics International, vol. 57, no. 4, pp. 608-613, 2015.

[66] C. E. Furlong, S. M. Suzuki, R. C. Stevens et al., "Human PON-1, a biomarker of risk of disease and exposure," ChemicoBiological Interactions, vol. 187, no. 1-3, pp. 355-361, 2010.

[67] D. Draganov, J. Teiber, C. Watson et al., "PON1 and oxidative stress in human sepsis and animal model of sepsis," in Advances in Experimental Medicine and Biology, vol. 660, pp. 89-97, Humana Press, 2010.

[68] M. Bajčetić, B. Otašević, N. B. Prekajski, S. Spasić, and I. Spasojević, "Antioxidative system in the erythrocytes of preterm neonates with sepsis: the effects of vitamin E supplementation," Annals of Clinical Biochemistry, vol. 51, no. 5, pp. 550-556, 2014.

[69] R. D. Higgins, G. Saade, R. A. Polin et al., "Evaluation and management of women and newborns with a maternal diagnosis of chorioamnionitis: summary of a workshop," Obstetrics \& Gynecology, vol. 127, no. 3, pp. 426-436, 2016.

[70] T. M. Randis, R. A. Polin, and G. Saade, "Chorioamnionitis: time for a new approach," Current Opinion in Pediatrics, vol. 29, no. 2, pp. 159-164, 2017.

[71] S. Perrone, M. L. Tataranno, S. Negro et al., "Placental histological examination and the relationship with oxidative stress in preterm infants," Placenta, vol. 46, pp. 72-78, 2016.

[72] H. E. Soydinc, M. E. Sak, O. Evliyaoglu et al., "Prolidase, matrix metalloproteinases 1 and 13 activity, oxidativeantioxidative status as a marker of preterm premature rupture of membranes and chorioamnionitis in maternal vaginal washing fluids," International Journal of Medical Sciences, vol. 10, no. 10, pp. 1344-1351, 2013.

[73] M. Kacerovsky, L. Tothova, R. Menon et al., "Amniotic fluid markers of oxidative stress in pregnancies complicated by preterm prelabor rupture of membranes," The Journal of Maternal-Fetal \& Neonatal Medicine, vol. 28, no. 11, pp. 1250-1259, 2014. 
[74] I. Musilova, L. Tothova, R. Menon et al., "Umbilical cord blood markers of oxidative stress in pregnancies complicated by preterm prelabor rupture of membranes," The Journal of Maternal-Fetal \& Neonatal Medicine, vol. 29, no. 12, pp. 1900-1910, 2016.

[75] M. Cernada, C. Bäuerl, E. Serna, M. C. Collado, G. P. Martínez, and M. Vento, "Sepsis in preterm infants causes alterations in mucosal gene expression and microbiota profiles compared to non-septic twins," Scientific Reports, vol. 6 , no. 1, article 25497, 2016.

[76] M. Cernada, E. Serna, C. Bauerl, M. C. Collado, G. PerezMartinez, and M. Vento, "Genome-wide expression profiles in very low birth weight infants with neonatal sepsis," Pediatrics, vol. 133, no. 5, pp. e1203-e1211, 2014.

[77] J. M. Knight, L. A. Davidson, D. Herman et al., "Non-invasive analysis of intestinal development in preterm and term infants using RNA-sequencing," Scientific Reports, vol. 4, no. 1, p. 5453, 2014.

[78] L. Srinivasan, G. Page, H. Kirpalani et al., "Genome-wide association study of sepsis in extremely premature infants," Archives of Disease in Childhood - Fetal and Neonatal Edition, vol. 102, no. 5, pp. F439-F445, 2017.

[79] P. Jiang, M. L. Jensen, M. S. Cilieborg et al., “Antibiotics increase gut metabolism and antioxidant proteins and decrease acute phase response and necrotizing enterocolitis in preterm neonates," PLoS One, vol. 7, no. 9, article e44929, 2012.

[80] C. Greenwood, A. L. Morrow, A. J. Lagomarcino et al., "Early empiric antibiotic use in preterm infants is associated with lower bacterial diversity and higher relative abundance of Enterobacter," The Journal of Pediatrics, vol. 165, no. 1, pp. 23-29, 2014.

[81] V. Mai, C. M. Young, M. Ukhanova et al., "Fecal microbiota in premature infants prior to necrotizing enterocolitis," PLoS One, vol. 6, no. 6, article e20647, 2011.

[82] C. M. Cotten, S. Taylor, B. Stoll et al., "Prolonged duration of initial empirical antibiotic treatment is associated with increased rates of necrotizing enterocolitis and death for extremely low birth weight infants," Pediatrics, vol. 123, no. 1, pp. 58-66, 2009.

[83] V. S. Kuppala, J. Meinzen-Derr, A. L. Morrow, and K. R. Schibler, "Prolonged initial empirical antibiotic treatment is associated with adverse outcomes in premature infants," The Journal of Pediatrics, vol. 159, no. 5, pp. 720-725, 2011.

[84] M. Valpacos, D. Arni, A. Keir et al., "Diagnosis and management of necrotizing enterocolitis: an international survey of neonatologists and pediatric surgeons," Neonatology, vol. 113, no. 2, pp. 170-176, 2018.

[85] B. P. Blackwood, C. J. Hunter, and J. Grabowski, "Variability in antibiotic regimens for surgical necrotizing enterocolitis highlights the need for new guidelines," Surgical Infections, vol. 18, no. 2, pp. 215-220, 2017.

[86] D. W. Scheifele, G. L. Ginter, E. Olsen, S. Fussell, and M. Pendray, "Comparison of two antibiotic regimens for neonatal necrotizing enterocolitis," The Journal of Antimicrobial Chemotherapy, vol. 20, no. 3, pp. 421-429, 1987.

[87] C. D. Downard, E. Renaud, S. D. St Peter et al., "Treatment of necrotizing enterocolitis: an American Pediatric Surgical Association Outcomes and Clinical Trials Committee systematic review," Journal of Pediatric Surgery, vol. 47, no. 11, pp. 2111-2122, 2012.
[88] D. Shah and J. K. H. Sinn, "Antibiotic regimens for the empirical treatment of newborn infants with necrotising enterocolitis," Cochrane Database of Systematic Reviews, no. 8, article CD007448, 2012.

[89] M. Pammi and G. Suresh, "Enteral lactoferrin supplementation for prevention of sepsis and necrotizing enterocolitis in preterm infants," Cochrane Database of Systematic Reviews, no. 6, article CD007137, 2017.

[90] M. Pammi and S. A. Abrams, "Oral lactoferrin for the prevention of sepsis and necrotizing enterocolitis in preterm infants," Cochrane Database of Systematic Reviews, no. 2, article CD007137, 2015.

[91] P. Manzoni, A. Dall'Agnola, D. Tomé et al., "Role of lactoferrin in neonates and infants: an update," American Journal of Perinatology, vol. 35, no. 6, pp. 561-565, 2018.

[92] M. Pammi and K. N. Haque, "Pentoxifylline for treatment of sepsis and necrotizing enterocolitis in neonates," Cochrane Database of Systematic Reviews, no. 3, article CD004205, 2015.

[93] R. Ozdemir, S. Yurttutan, F. N. Sar1 et al., "Antioxidant effects of $\mathrm{N}$-acetylcysteine in a neonatal rat model of necrotizing enterocolitis," Journal of Pediatric Surgery, vol. 47, no. 9, pp. 1652-1657, 2012.

[94] L. Marseglia, G. D'Angelo, S. Manti et al., "Oxidative stressmediated damage in newborns with necrotizing enterocolitis: a possible role of melatonin," American Journal of Perinatology, vol. 32, no. 10, pp. 905-909, 2015.

[95] A. Galano, D. X. Tan, and R. J. Reiter, "Melatonin as a natural ally against oxidative stress: a physicochemical examination," Journal of Pineal Research, vol. 51, no. 1, pp. 1-16, 2011.

[96] R. J. Reiter, D. X. Tan, S. Rosales-Corral, and L. C. Manchester, "The universal nature, unequal distribution and antioxidant functions of melatonin and its derivatives," Mini Reviews in Medicinal Chemistry, vol. 13, no. 3, pp. 373-384, 2013.

[97] E. Gitto, R. J. Reiter, S. P. Cordaro et al., "Oxidative and inflammatory parameters in respiratory distress syndrome of preterm newborns: beneficial effects of melatonin," American Journal of Perinatology, vol. 21, no. 4, pp. 209-216, 2004.

[98] E. Gitto, R. J. Reiter, A. Amodio et al., "Early indicators of chronic lung disease in preterm infants with respiratory distress syndrome and their inhibition by melatonin," Journal of Pineal Research, vol. 36, no. 4, pp. 250-255, 2004.

[99] F. M. El-Gendy, M. A. El-Hawy, and M. G. Hassan, "Beneficial effect of melatonin in the treatment of neonatal sepsis," The Journal of Maternal-Fetal \& Neonatal Medicine, vol. 31, no. 17, pp. 2299-2303, 2017.

[100] M. El Frargy, H. M. El-sharkawy, and G. F. Attia, "Use of melatonin as an adjuvant therapy in neonatal sepsis," Journal of Neonatal-Perinatal Medicine, vol. 8, no. 3, pp. 227-232, 2015.

[101] E. Gitto, C. Romeo, R. J. Reiter et al., "Melatonin reduces oxidative stress in surgical neonates," Journal of Pediatric Surgery, vol. 39, no. 2, pp. 184-189, 2004.

[102] A. R. El-Mashad, H. Elmahdy, M. El-Dib, M. Elbatch, and H. Aly, "Can melatonin be used as a marker for neonatal sepsis?," The Journal of Maternal-Fetal \& Neonatal Medicine, vol. 29, no. 17, pp. 2870-2873, 2016.

[103] G. D’Angelo, L. Marseglia, R. J. Reiter, G. Buonocore, and E. Gitto, "Melatonin and neonatal sepsis: a promising antioxidant adjuvant agent," American Journal of Perinatology, vol. 34, no. 14, pp. 1382-1388, 2017. 
[104] E. Harris, S. M. Schulzke, and S. K. Patole, "Pentoxifylline in preterm neonates: a systematic review," Pediatric Drugs, vol. 12, no. 5, pp. 301-311, 2010.

[105] A. E. Shabaan, N. Nasef, B. Shouman, I. Nour, A. Mesbah, and H. Abdel-Hady, "Pentoxifylline therapy for late-onset sepsis in preterm infants: a randomized controlled trial," The Pediatric Infectious Disease Journal, vol. 34, no. 6, pp. e143-e148, 2015.

[106] A. Akdag, U. Dilmen, K. Haque, D. Dilli, O. Erdeve, and T. Goekmen, "Role of pentoxifylline and/or IgM-enriched intravenous immunoglobulin in the management of neonatal sepsis," American Journal of Perinatology, vol. 31, no. 10, pp. 905-912, 2014.

[107] E. M. Speer, D. J. Dowling, L. S. Ozog et al., "Pentoxifylline inhibits TLR- and inflammasome-mediated in vitro inflammatory cytokine production in human blood with greater efficacy and potency in newborns," Pediatric Research, vol. 81, no. 5, pp. 806-816, 2017.

[108] J. L. Gifford, H. N. Hunter, and H. J. Vogel, "Lactoferricin: a lactoferrin-derived peptide with antimicrobial, antiviral, antitumor and immunological properties," Cellular and Molecular Life Sciences, vol. 62, no. 22, pp. 2588-2598, 2005.

[109] P. Manzoni, M. Rinaldi, S. Cattani et al., "Bovine lactoferrin supplementation for prevention of late-onset sepsis in very low-birth-weight neonates: a randomized trial," JAMA, vol. 302, no. 13, pp. 1421-1428, 2009.

[110] L. Decembrino, M. DeAmici, A. De Silvestri, P. Manzoni, P. Paolillo, and M. Stronati, "Plasma lactoferrin levels in newborn preterm infants with sepsis," The Journal of MaternalFetal \& Neonatal Medicine, vol. 30, no. 23, pp. 2890-2893, 2017.

[111] L. P. Brion, E. F. Bell, and T. S. Raghuveer, "Vitamin E supplementation for prevention of morbidity and mortality in preterm infants," Cochrane Database of Systematic Reviews, no. 4, article CD003665, 2003.

[112] B. A. Darlow and N. C. Austin, "Selenium supplementation to prevent short-term morbidity in preterm neonates," Cochrane Database of Systematic Reviews, no. 4, article CD003312, 2003.

[113] S. Bhatnagar, N. Wadhwa, S. Aneja et al., "Zinc as adjunct treatment in infants aged between 7 and 120 days with probable serious bacterial infection: a randomised, double-blind, placebo-controlled trial," Lancet, vol. 379, no. 9831, pp. 2072-2078, 2012.

[114] G. Demirel, I. H. Celik, F. E. Canpolat, O. Erdeve, S. S. Oguz, and U. Dilmen, "The effects of ibuprofen on sepsis parameters in preterm neonates," Early Human Development, vol. 88, no. 4, pp. 195-196, 2012.

[115] N. Nakamoto, S. Tada, K. Kameyama et al., "A free radical scavenger, edaravone, attenuates steatosis and cell death via reducing inflammatory cytokine production in rat acute liver injury," Free Radical Research, vol. 37, no. 8, pp. 849-859, 2003.

[116] J. I. Noor, T. Ikeda, K. Mishima et al., "Short-term administration of a new free radical scavenger, edaravone, is more effective than its long-term administration for the treatment of neonatal hypoxic-ischemic encephalopathy," Stroke, vol. 36, no. 11, pp. 2468-2474, 2005.

[117] S. Kato, M. H. Hussein, H. Kakita et al., "Edaravone, a novel free radical scavenger, reduces high-mobility group box 1 and prolongs survival in a neonatal sepsis model," Shock, vol. 32, no. 6, pp. 586-592, 2009.
[118] S. Yamaguchi, M. H. Hussein, G. A. E. H. Daoud et al., "Edaravone, a hydroxyl radical scavenger, ameliorates the severity of pulmonary hypertension in a porcine model of neonatal sepsis," The Tohoku Journal of Experimental Medicine, vol. 223, no. 4, pp. 235-241, 2011.

[119] H. Nakamoto, Y. Aihara, K. Yamaguchi, T. Kawamata, and Y. Okada, "Efficacy, safety, and outcomes in 17 pediatric cases treated with the free radical scavenger edaravone," Child's Nervous System, vol. 31, no. 9, pp. 1533-1540, 2015.

[120] M. Browatzki, J. Schmidt, W. Kübler, and R. Kranzhöfer, "Endothelin-1 induces interleukin-6 release via activation of the transcription factor NF- $\kappa \mathrm{B}$ in human vascular smooth cells," Basic Research in Cardiology, vol. 95, no. 2, pp. 98$105,2000$.

[121] J. Figueras-Aloy, L. Gómez-Lopez, J. M. Rodríguéz-Miguélez et al., "Plasma endothelin-1 and clinical manifestations of neonatal sepsis," Journal of Perinatal Medicine, vol. 32, no. 6, pp. 522-526, 2004.

[122] A. A. Rosenberg, J. Kennaugh, S. L. Koppenhafer, M. Loomis, B. A. Chatfield, and S. H. Abman, "Elevated immunoreactive endothelin-1 levels in newborn infants with persistent pulmonary hypertension," The Journal of Pediatrics, vol. 123, no. 1, pp. 109-114, 1993.

[123] T. Goto, M. H. Hussein, S. Kato et al., "Endothelin receptor antagonist attenuates inflammatory response and prolongs the survival time in a neonatal sepsis model," Intensive Care Medicine, vol. 36, no. 12, pp. 2132-2139, 2010.

[124] T. Goto, M. H. Hussein, S. Kato et al., "Endothelin receptor antagonist attenuates oxidative stress in a neonatal sepsis piglet model," Pediatric Research, vol. 72, no. 6, pp. 600605, 2012.

[125] H. F. Galley, "Bench-to-bedside review: Targeting antioxidants to mitochondria in sepsis," Crtitical Care, vol. 14, no. 4, p. 230, 2010. 


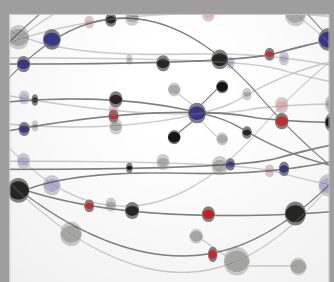

The Scientific World Journal
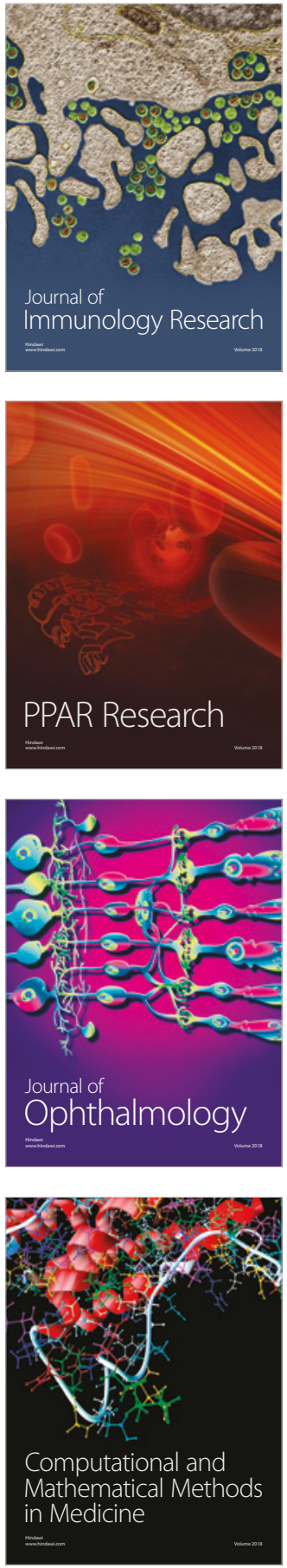

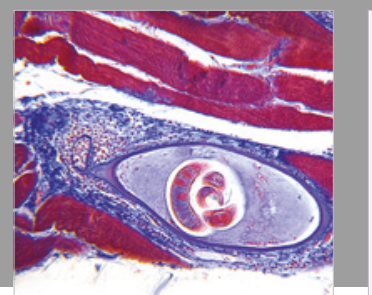

Gastroenterology Research and Practice

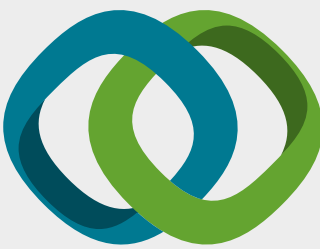

\section{Hindawi}

Submit your manuscripts at

www.hindawi.com
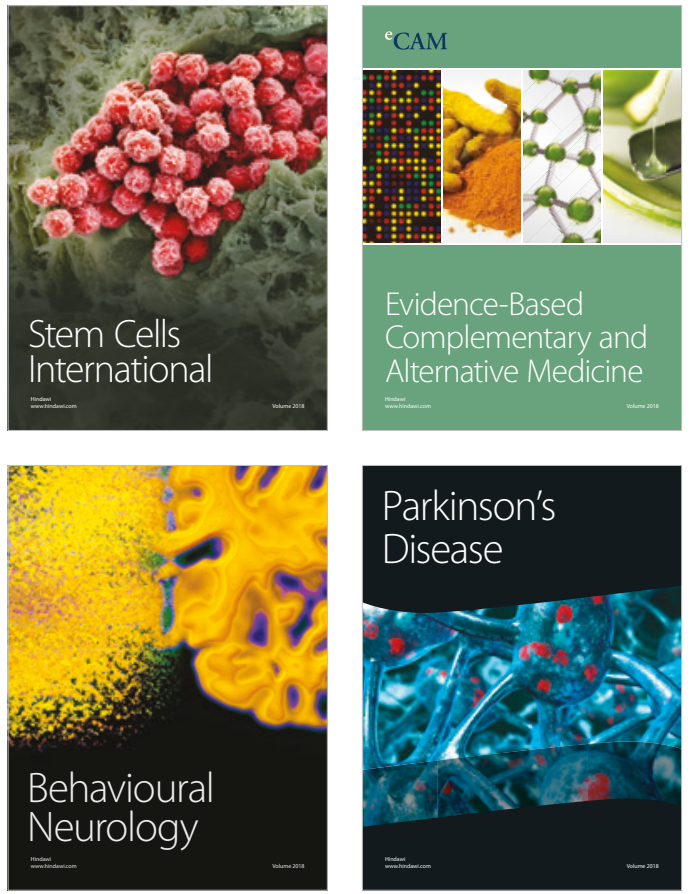

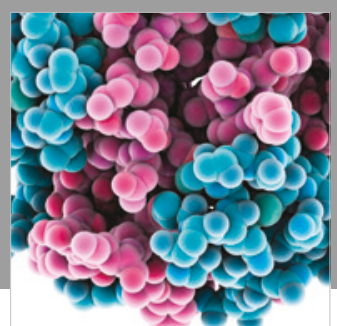

ournal of

Diabetes Research

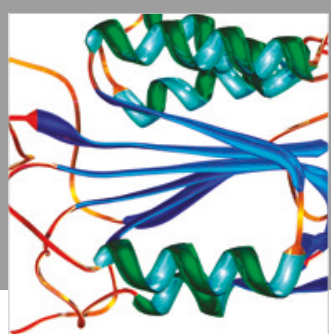

Disease Markers
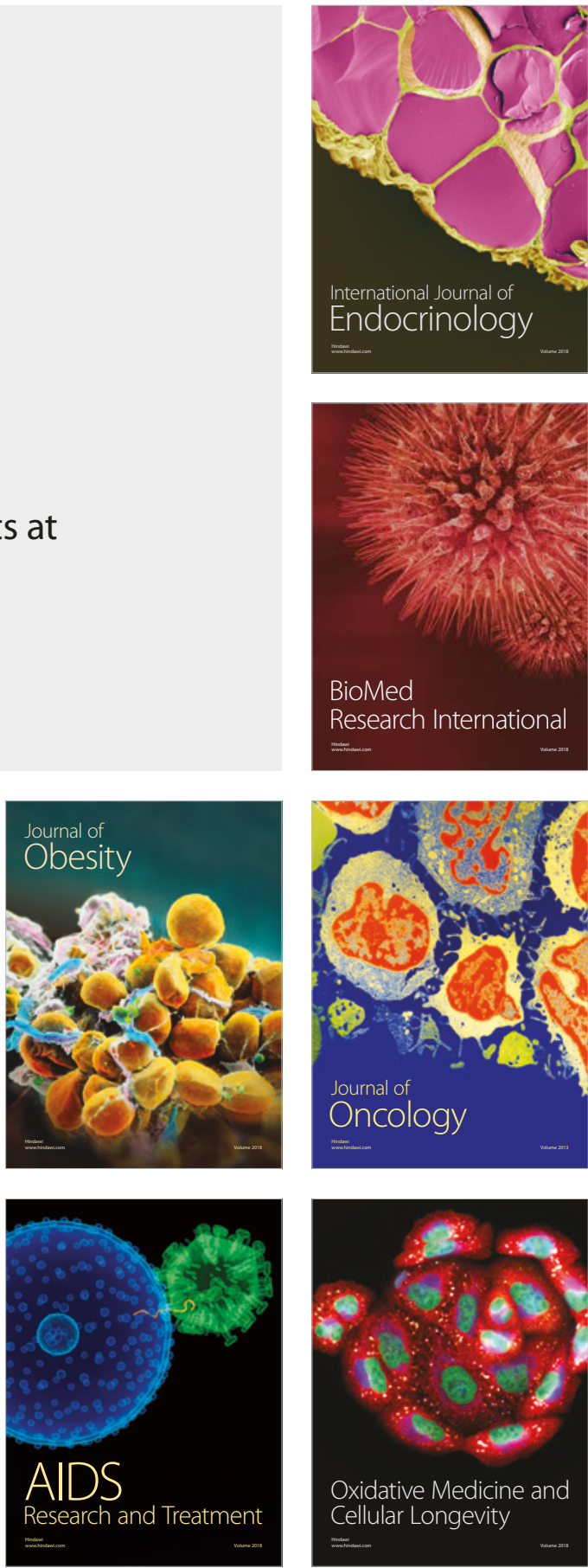